\title{
Voluntary Is Better Than Involuntary Cough Peak Flow for Predicting Re-Intubation After Scheduled Extubation in Cooperative Subjects
}

\author{
Jun Duan MD, Jinhua Liu RN, Meiling Xiao RN, Xiangmei Yang RN, \\ Jinxing $\mathrm{Wu} \mathrm{MD}$, and Lintong Zhou MD
}

\begin{abstract}
BACKGROUND: In this study, we compared the predictive accuracy of voluntary cough peak flow (V-CPF) and involuntary cough peak flow (IV-CPF) for re-intubation in mechanically ventilated subjects. METHODS: Endotracheally intubated patients who passed a spontaneous breathing trial and assessment of readiness for extubation were enrolled. Before extubation, V-CPF and IV-CPF were measured. Re-intubation was recorded at $72 \mathrm{~h}$ after extubation. RESULTS: A total of 115 extubations in 106 cooperative subjects (including 9 subjects with second extubation) and 5 extubations in 5 uncooperative subjects were recorded. At $72 \mathrm{~h}, 20(17.4 \%)$ and $1(25 \%)$ instances of re-intubation occurred in cooperative and uncooperative subjects, respectively. In cooperative subjects, those who had been successfully extubated had higher V-CPF than re-intubated subjects $(81.3 \pm 41.4$ vs $51.3 \pm 31.7, P=.003)$. However, rates were not significantly different with IV-CPF $(70.9 \pm 39.8$ vs $55.7 \pm 37.9, P=.121)$. Areas under the curve of the receiver operating characteristic in $\mathrm{V}$-CPF and IV-CPF were $0.743 \pm 0.057$ and $0.632 \pm 0.069(P<.001$ and $P=.058$, respectively, compared with area under the curve $=0.5)$. V-CPF had higher predictive accuracy for re-intubation than IV-CPF $(P=.034)$. In subjects with a lower quartile and third quartile V-CPF $(\leq 43.2$ $\mathrm{L} / \mathrm{min}$ and 43.2-68.4 L/min, respectively), V-CPF was similar to IV-CPF. However, in second quartile and upper quartile $\mathrm{V}-\mathrm{CPF}(68.4-99.0 \mathrm{~L} / \mathrm{min}$ and $>99.0 \mathrm{~L} / \mathrm{min}$, respectively), V-CPF was higher than IV-CPF $(82.1 \pm 9.6$ vs $66.6 \pm 19.5 \mathrm{~L} / \mathrm{min}, P<.001 ; 135.5 \pm 29.8$ vs $116.2 \pm 38.2 \mathrm{~L} / \mathrm{min}$, $P=.006$, respectively $)$. Overall, V-CPF was higher than IV-CPF $(76.0 \pm 41.4$ vs $68.2 \pm 39.7$, $P=.003)$. In uncooperative subjects, the IV-CPF was higher than V-CPF $(40.2 \pm 10.2$ vs 79.2 \pm 29.0 , $P=.042)$. CONCLUSIONS: V-CPF is noninvasive. It is much more accurate than IV-CPF as a predictor of re-intubation in cooperative patients because the IV-CPF may underestimate cough strength in patients with high V-CPF. However, it is unclear which is optimal for use in uncooperative patients. Key words: cough peak flow; spontaneous breathing trial; extubation; re-intubation; tracheotomy. [Respir Care 2014;59(11):1643-1651. (c) 2014 Daedalus Enterprises]
\end{abstract}

Introduction

The spontaneous breathing trial (SBT) is most frequently used for assessing recovery from respiratory failure in me-

The authors are affiliated with the Department of Respiratory Medicine, First Affiliated Hospital of Chongqing Medical University, Chongqing, People's Republic of China.

This study was supported by State Key Clinical Specialty Construction Project funding. The authors have disclosed no conflicts of interest. chanically ventilated patients. Guidelines for weaning from mechanical ventilation recommend removal of the endotracheal tube when a patient has passed an SBT.1-3 Nevertheless, $12.4-21 \%$ of patients require re-intubation within

\footnotetext{
Correspondence: Jun Duan MD, Department of Respiratory Medicine, First Affiliated Hospital of Chongqing Medical University, Youyi Road 1, Yuzhong District, Chongqing 400016, People's Republic of China. E-mail: duanjun412589@163.com.
}

DOI: $10.4187 /$ respcare.03045 
48-72 $\mathrm{h}$, although they have a successful SBT.4-8 This results from many reasons, such as weak cough, large amount of secretions, advanced age, impaired neurological status, or laryngospasm. ${ }^{9,10}$ Furthermore, re-intubation is associated with a 5-fold increase in the relative odds of death and a 2-fold increase in median ICU and hospital stay, as well as institutional costs. ${ }^{11}$ Thus, avoiding reintubation is important.

Many studies have reported that voluntary cough peak flow (V-CPF), measured before extubation in patients who passed a SBT, had a high accuracy in predicting successful weaning from intubation. ${ }^{12-15}$ Patients with low V-CPF had a high risk of re-intubation after scheduled extubation. $\mathrm{Su}$ et $\mathrm{al}^{16}$ reported that involuntary cough peak flow (IVCPF), also measured before extubation, showed similar accuracy in predicting re-intubation. However, which of the two methods is more accurate in predicting re-intubation is unclear. Therefore, we designed this study to compare the predictive abilities of V-CPF and IV-CPF.

\section{Methods}

The study enrolled the subjects as follows: (1) age $\geq 18$ $y$, (2) duration of mechanical ventilation $\geq 24 \mathrm{~h}$, (3) endotracheal intubation, and (4) a successful SBT and readiness for extubation. Written informed consent was obtained from the subjects or their families. The investigational review board of our hospital (First Affiliated Hospital of Chongqing Medical University) approved this study.

All subjects on mechanical ventilation were managed by our hospital protocol. Strategies to prevent ventilatorassociated pneumonia (eg, elevation of the head of the bed, hand hygiene, and oral hygiene) were used in every subject. Sedation was routinely managed to reach a Ramsay score of 3-4 when subjects became agitated, subjectventilator asynchrony occurred, or other clinical conditions occurred in which the subjects needed to relax. Sedation was interrupted each morning. If the subject remained calm, sedation was stopped. If not, sedation was continued. ${ }^{17}$

For weaning attempts, they were screened every morning as follows: improvement in the underlying condition that led to acute respiratory failure, $\mathrm{P}_{\mathrm{aO}_{2}} \geq 60 \mathrm{~mm} \mathrm{Hg}$ with $\mathrm{F}_{\mathrm{IO}_{2}} \leq 0.5$, PEEP $\leq 5 \mathrm{~cm} \mathrm{H}_{2} \mathrm{O}$, temperature $\leq 38^{\circ} \mathrm{C}$, systolic blood pressure between 90 and $180 \mathrm{~mm} \mathrm{Hg}$ (without vasopressor therapy or with only a low-dose vasopressor such as dopamine or dobutamine $\leq 5 \mu \mathrm{g} / \mathrm{kg} / \mathrm{min}$ ), heart rate $\leq 140$ beats/min, and breathing frequency $\leq 30$ breaths/min. ${ }^{1}$

If the subject met the initial screening criteria for extubation, an SBT was performed once daily for $120 \mathrm{~min}$. The SBT was carried out in pressure support mode. The support pressure was set at $6 \mathrm{~cm} \mathrm{H}_{2} \mathrm{O}$ for an inner diameter of

\section{QUICK LOOK}

\section{Current knowledge}

Voluntary cough peak flow measured before extubation coupled with a successful spontaneous breathing trial has been shown to improve prediction of successful withdrawal from mechanical ventilation. The cough peak flow is a measure of the ability to clear secretions and protect the airway.

\section{What this paper contributes to our knowledge}

Voluntary cough peak flow is a more accurate predictor of successful extubation than involuntary cough peak flow. Both measures are noninvasive; however, involuntary peak cough flow appears to underestimate cough strength.

the endotracheal tube $\geq 7.5 \mathrm{~mm}$ and $8 \mathrm{~cm} \mathrm{H}_{2} \mathrm{O}$ for $<7.5 \mathrm{~mm}$. The subject failed the SBT if one of the following occurred: breathing frequency $\geq 35$ breaths $/ \mathrm{min}$, frequency/tidal volume (rapid shallow breathing index) $\geq 105, \mathrm{~S}_{\mathrm{pO}_{2}}<90 \%$ at $\mathrm{F}_{\mathrm{IO}_{2}} \geq 0.5$, heart rate $\geq 140$ or $\leq 50$ beats/min, systolic blood pressure $\geq 180$ or $\leq 90$ $\mathrm{mm} \mathrm{Hg}, \mathrm{pH} \leq 7.3$, diminishing consciousness or diaphoresis, and clinical signs indicating respiratory muscle fatigue, labored breathing, or both.

When subjects passed the SBT before extubation, we measured the V-CPF and IV-CPF with a spirometer (Chestgraph HI-101, Chest MI, Tokyo, Japan; Fig. 1). Measurements were done according to the sequence of enrollment in the study: in odd-numbered subjects, we measured the V-CPF first, let the subject rest for $10 \mathrm{~min}$ as a washout period, and then measured the IV-CPF. In even-numbered subjects, the order of V-CPF and IV-CPF was switched. Before measurement, the subjects were positioned at $30-$ $45^{\circ}$ in bed, secretions were removed by suction, and subjects were oxygenated with $100 \%$ oxygen for $2 \mathrm{~min}$. To measure V-CPF, subjects were coached to cough through the endotracheal tube spirometer with as much effort as possible. The intervals between each measure were $30-$ $60 \mathrm{~s}$. The best of three measurements was recorded as the $\mathrm{V}$-CPF. To measure the IV-CPF, $2 \mathrm{~mL}$ of normal saline was rapidly instilled into the endotracheal tube at the endinspiratory point through the Y-shaped tube (see Fig. 1). ${ }^{16}$ As with V-CPF measurements, the best of three measurements was used as the recorded value for IV-CPF.

We assessed each subject's neurological status every morning according to the Glasgow coma scale, including eye response 4 score, verbal response 5 score, and motor response 6 score. Because the endotracheal tube was in the subject's airway, the verbal response was assessed as follows. We asked 2-3 simple questions, which the subject 


\section{Cough Peak Flow for Predicting Re-Intubation}

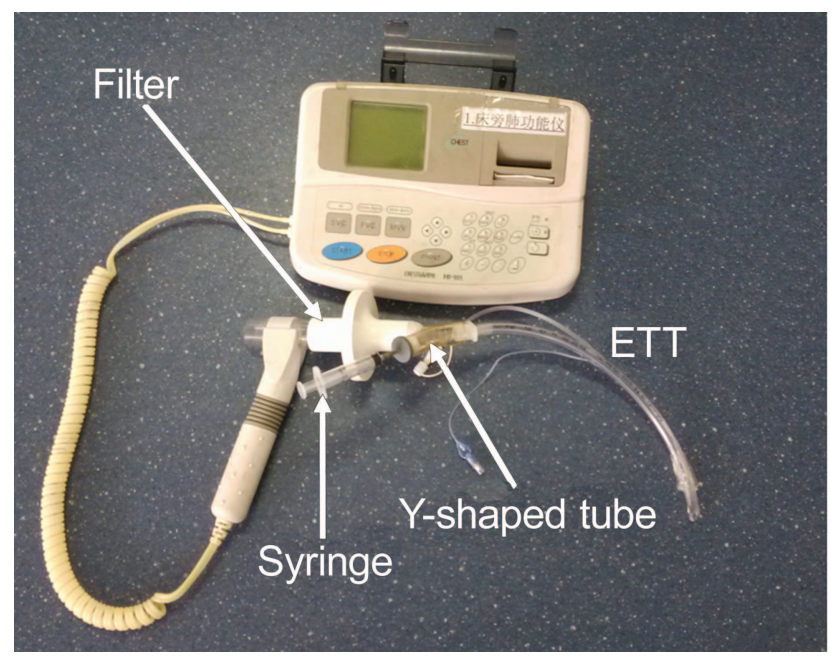

Fig. 1. The spirometer was connected to the endotracheal tube (ETT) by a filter and Y-shaped tube. One end of the $Y$-shaped tube was connected to the ETT, one end was connected to the filter, and another end was sealed by a rubber plug. The syringe was used for instillation of $2 \mathrm{~mL}$ of normal saline when involuntary cough peak flow (IV-CPF) was measured. Before voluntary cough peak flow (V-CPF) measurement, the syringe was removed.

could answer by nodding or shaking the head for yes or no. If all responses were rapid and the answers were correct, we scored 5. If all responses were slow and the answers were correct, we scored 4 . If part of the answers were correct, we scored 3. If no answers were correct, we scored 2. For no response, we scored 1. Additionally, we classified the subjects with Glasgow coma scale $>13$ as cooperative subjects and Glasgow coma scale $\leq 13$ as uncooperative subjects.

Criteria for re-intubation were: (1) breathing frequency $>30$ breaths/min; (2) $\mathrm{S}_{\mathrm{pO}_{2}}<90 \%$ with $\mathrm{F}_{\mathrm{IO}_{2}}>0.4$; (3) pH $<7.30$; (4) an increase of $>10 \mathrm{~mm} \mathrm{Hg}$ in $\mathrm{P}_{\mathrm{aCO}_{2}}$; (5) heart rate $>120$ or $<50$ beats/min; (6) systolic blood pressure $>180$ or $<90 \mathrm{~mm} \mathrm{Hg}$; and (7) diminished consciousness, diaphoresis, clinical signs of respiratory muscle fatigue, labored breathing, or any combination of these. Noninvasive mechanical ventilation was allowed if the attending physicians thought the subjects would benefit. When there was respiratory failure caused by weak cough strength and large amounts of secretions, the subject received an emergency tracheotomy if there was enough time. These subjects were also defined as re-intubation subjects regardless of whether they also received invasive mechanical ventilation. Re-intubation was recorded up to $72 \mathrm{~h}$ after extubation.

The diagnostic accuracy of V-CPF and IV-CPF was analyzed by receiver operating characteristic curve (SPSS 17.0, SPSS, Chicago, Illinois). The Hanley and McNeil method was used to compare the area under the curve of receiver operating characteristic in V-CPF and IV-CPF. ${ }^{18}$ The cough peak flow values for successful and unsuccess- ful extubation subjects were compared by independent sample $t$ test. Comparisons of V-CPF and IV-CPF in different $\mathrm{V}-\mathrm{CPF}$ groups were analyzed by paired sample $t$ test. The optimal cut-off value was chosen by the maximum Youden index. ${ }^{19} P<.05$ was considered significant.

\section{Results}

We recorded 115 extubations in 106 cooperative subjects (including 9 subjects with second extubation) and 5 extubations in 5 uncooperative subjects between October 2011 and June 2013. Finally, we recorded 20 instances of re-intubation in cooperative subjects and one instance of re-intubation in uncooperative subjects, respectively. In cooperative subjects, 5 subjects ( 3 for invasive mechanical ventilation and 2 for suction only) who underwent tracheotomy were also classified as re-intubation subjects.

The clinical characteristics of the cooperative subjects are summarized in Table 1. The successful extubation subjects had shorter duration of mechanical ventilation $(5.80 \pm 5.55$ vs $9.58 \pm 5.84, P=.007)$, higher tidal volume (435 \pm 142 vs $349 \pm 96, P=.01)$, and higher V-CPF $(81.3 \pm 41.4$ vs $51.3 \pm 31.7, P=.003)$ before extubation. However, the IV-CPF did not reach significant difference.

The results of the V-CPF and IV-CPF analyzed by receiver operating characteristic curves are summarized in Table 2 and Figure 2. The diagnostic accuracy was significantly higher in V-CPF compared with IV-CPF $(P=.034)$. When the 2 subjects who underwent tracheotomy only for suction were excluded, $P=.01$.

Table 3 and Figure 3 show the differences in four categories of V-CPF. In subjects with lower quartile and third quartile $\mathrm{V}-\mathrm{CPF}$, the $\mathrm{V}-\mathrm{CPF}$ was similar with IV-CPF. In subjects with second and upper quartile $\mathrm{V}-\mathrm{CPF}$, the $\mathrm{V}$ $\mathrm{CPF}$ was higher than IV-CPF $(82.1 \pm 9.6$ vs $66.6 \pm 19.5 \mathrm{~L} /$ $\min , P<.001 ; 135.5 \pm 29.8$ vs $116.2 \pm 38.2 \mathrm{~L} / \mathrm{min}$, $P=.006$, respectively). Overall, the $\mathrm{V}-\mathrm{CPF}$ was higher than IV-CPF $(76.0 \pm 41.4$ vs $68.2 \pm 39.7, P=.003)$.

Table 4 and Figure 4 summarize the clinical characteristics of uncooperative subjects. Only 1 subject required re-intubation. The V-CPF was lower than IV-CPF $(40.2 \pm 10.2$ vs $79.2 \pm 29.0, P=.04)$.

\section{Discussion}

Current guidelines recommend the removal of an endotracheal tube after a successful SBT. ${ }^{1-3}$ However, it fails to evaluate the patient's airway protection. The CPF has also been introduced to evaluate airway protection. ${ }^{12-16}$ It has good sensitivity and specificity for predicting re-intubation after extubation when a patient has passed a SBT. Our findings are thus in agreement with those of previous studies in cooperative patients. With the cut-off value of 62.4 


\section{Cough Peak Flow for Predicting Re-Intubation}

Table 1. Characteristics of the Cooperative Subjects

\begin{tabular}{|c|c|c|c|}
\hline Subject Characteristics & $\begin{array}{l}\text { Extubation Success } \\
\qquad(N=95)\end{array}$ & $\begin{array}{l}\text { Re-intubation } \\
\quad(N=20)\end{array}$ & $P$ \\
\hline Age $(y)$ & $68.42 \pm 15.12$ & $73.95 \pm 15.43$ & .14 \\
\hline Male/female & $64 / 31$ & $10 / 10$ & .11 \\
\hline APACHE II score at initial intubation & $24.2 \pm 6.7$ & $24.3 \pm 6.6$ & $>.99$ \\
\hline \multicolumn{4}{|l|}{ Causes for initial intubation } \\
\hline COPD exacerbation & 54 & 7 & .09 \\
\hline Pneumonia & 18 & 7 & .14 \\
\hline ARDS & 12 & 2 & $>.99$ \\
\hline Postoperative acute respiratory failure & 6 & 2 & .63 \\
\hline Other & 5 & 2 & .35 \\
\hline Duration of mechanical ventilation before extubation (d) & $5.80 \pm 5.55$ & $9.58 \pm 5.84$ & .007 \\
\hline \multicolumn{4}{|l|}{ Data just collected before extubation } \\
\hline $\mathrm{GCS}=14$ & 7 & 2 & .65 \\
\hline $\mathrm{GCS}=15$ & 88 & 18 & .65 \\
\hline Breathing frequency (breaths/min) & $23.4 \pm 5.0$ & $24.7 \pm 3.7$ & .30 \\
\hline Tidal volume $(\mathrm{mL})$ & $435 \pm 142$ & $349 \pm 96$ & .01 \\
\hline Minute ventilation (L) & $9.6 \pm 3.0$ & $8.7 \pm 2.8$ & .23 \\
\hline Breathing frequency/tidal volume & $62 \pm 22$ & $71 \pm 18$ & .07 \\
\hline Heart rate (beats/min) & $95 \pm 15$ & $101 \pm 18$ & .14 \\
\hline Systolic blood pressure $(\mathrm{mm} \mathrm{Hg})$ & $128 \pm 18$ & $124 \pm 21$ & .39 \\
\hline Diastolic blood pressure $(\mathrm{mm} \mathrm{Hg})$ & $76 \pm 11$ & $72 \pm 9$ & .08 \\
\hline $\mathrm{pH}$ & $7.43 \pm 0.05$ & $7.44 \pm 0.07$ & .64 \\
\hline $\mathrm{P}_{\mathrm{aCO}_{2}}(\mathrm{~mm} \mathrm{Hg})$ & $46.8 \pm 12.4$ & $47.3 \pm 15.0$ & .86 \\
\hline $\mathrm{P}_{\mathrm{aO}_{2}}(\mathrm{~mm} \mathrm{Hg})$ & $90 \pm 21$ & $89 \pm 21$ & .86 \\
\hline $\mathrm{F}_{\mathrm{IO}_{2}}$ & $0.41 \pm 0.05$ & $0.43 \pm 0.05$ & .27 \\
\hline $\mathrm{P}_{\mathrm{aO}_{2}} / \mathrm{F}_{\mathrm{IO}_{2}}$ & $222 \pm 63$ & $212 \pm 55$ & .51 \\
\hline \multirow[t]{2}{*}{$\mathrm{V}-\mathrm{CPF}(\mathrm{L} / \mathrm{min})$} & $81.3 \pm 41.4$ & $51.3 \pm 31.7$ & .003 \\
\hline & $81.3 \pm 41.4^{*}$ & $51.1 \pm 33.3$ & .004 \\
\hline \multirow[t]{2}{*}{ IV-CPF (L/min) } & $70.9 \pm 39.8$ & $55.7 \pm 37.9$ & .12 \\
\hline & $70.9 \pm 39.8^{*}$ & $58.0 \pm 39.3$ & .21 \\
\hline $\begin{array}{l}\text { * In the re-intubation group, } 2 \text { patients with tracheotomy only for suction we } \\
\text { APACHE II = Acute Physiology and Chronic Health Evaluation II } \\
\text { GCS = Glasgow coma scale } \\
\text { V-CPF = voluntary cough peak flow } \\
\text { IV-CPF = involuntary cough peak flow }\end{array}$ & & & \\
\hline
\end{tabular}

$\mathrm{L} / \mathrm{min}$ in $\mathrm{V}-\mathrm{CPF}$, it has $85 \%$ sensitivity and $64.2 \%$ specificity to predict re-intubation. However, using the SBT introduces another problem. In the low cough population, it is difficult to make the decision to extubate when a patient passes a spontaneous breath trial. In our opinion, the endotracheal tube should be removed. However, we suggest it is necessary to pay more attention to airway management such as adequate humidification, chest phys-

Table 2. Analysis of V-CPF and IV-CPF by ROC Curves and Optimal Cut-Off Values in Cooperative Subjects

\begin{tabular}{|c|c|c|c|c|c|c|}
\hline Cough Peak Flow & $\begin{array}{c}\text { Optimal } \\
\text { Cut-Off Value } \\
\text { (L/min) }\end{array}$ & $\begin{array}{c}\text { Sensitivity } \\
(\%)\end{array}$ & $\begin{array}{c}\text { Specificity } \\
(\%)\end{array}$ & $\begin{array}{c}\text { AUC } \\
(\text { mean } \pm \mathrm{SE})\end{array}$ & $\begin{array}{c}\text { AUC } \\
(95 \% \mathrm{CI})\end{array}$ & $P$ \\
\hline $\mathrm{V}-\mathrm{CPF}$ & 62.4 & 85.0 & 64.2 & $0.743 \pm 0.057$ & $0.653-0.820$ & $<.001$ \\
\hline IV-CPF & 49.8 & 70.0 & 66.3 & $0.632 \pm 0.069$ & $0.537-0.720$ & .06 \\
\hline \multicolumn{7}{|c|}{$\begin{array}{l}\mathrm{V}-\mathrm{CPF}=\text { voluntary cough peak flow } \\
\mathrm{IV}-\mathrm{CPF}=\text { involuntary cough peak flow } \\
\text { ROC = receiver operating characteristic } \\
\text { AUC = area under the curve }\end{array}$} \\
\hline
\end{tabular}




\section{Cough Peak Flow for Predicting Re-Intubation}

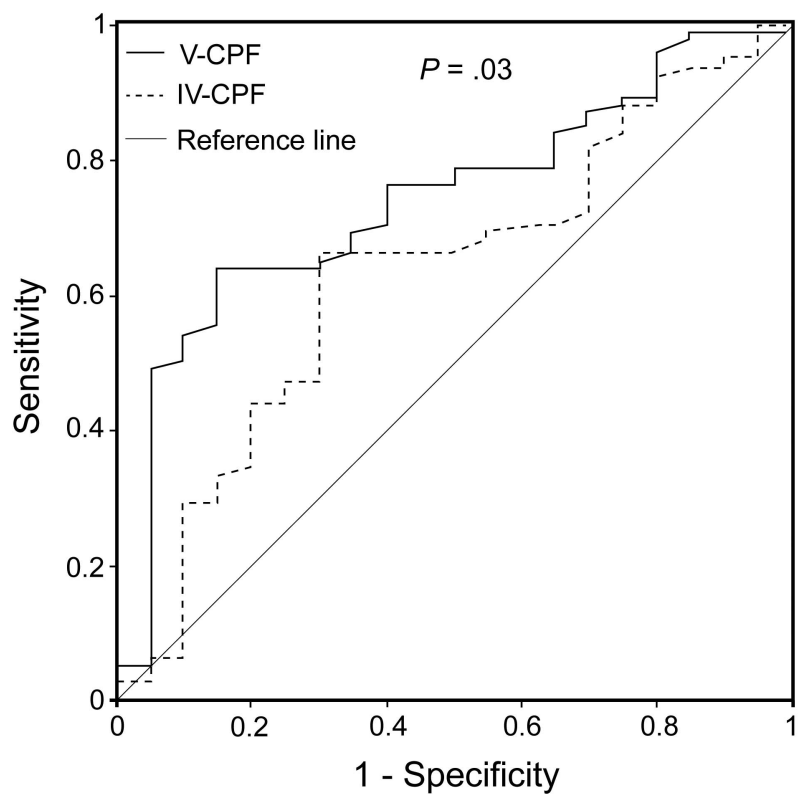

Fig. 2. Comparison of the area under the curve of the receiver operating characteristic in voluntary cough peak flow (V-CPF) and involuntary cough peak flow (IV-CPF) in cooperative subjects.

ical therapy, nasotracheal suctioning, and even tracheotomy in some very low cough peak flow patients.

However, as compared with the results from the study by $\mathrm{Su}$ et al, ${ }^{16} \mathrm{IV}-\mathrm{CPF}$ was only predictive of re-intubation after scheduled extubation in cooperative subjects (Table $2)$. In their study, $94(62.7 \%)$ subjects were surgery patients and $17(53.1 \%)$ received re-intubation. However, in our study, most subjects had an exacerbation of COPD. The different populations may result in different predictive accuracy by IV-CPF.

In this study, we used a revised definition of re-intubation after scheduled extubation as the main weaning outcome. This is different from previous studies, which recorded only re-intubation through the mouth or nose..$^{12-16}$ In our study, we included re-intubation not only through the mouth or nose but also through a tracheotomy (even a tracheostomy tube placed solely for suction). There is no question that tracheotomy subjects should be classified as re-intubation if they received invasive mechanical ventilation. However, this classification may be controversial if the tracheostomy tube was placed only for suction. Occasionally, endotracheal intubation was only necessitated by apnea in patients with an inability to remove secretions..$^{20,21}$ In this population, clinicians can easily remove the secretions through the endotracheal tube. If hypoxemia and hypercapnia are relieved by suction alone, invasive mechanical ventilation is unnecessary. However, another problem is difficulty in extubation if cough ability cannot be recovered. Therefore, if apnea occurs in subjects with a weak cough ability, emergency tracheotomy may be a good choice. Thus, though 2 subjects received a tracheostomy only for suction, we also classified them as re-intubation subjects.

To our knowledge, this is the first study to compare the ability of V-CPF and IV-CPF to predict weaning outcomes. We demonstrated that V-CPF was better than IV-CPF for prediction of re-intubation in cooperative subjects. Furthermore, we observed that some high V-CPF subjects had low IV-CPF (Table 3 and Figs. 3). However, the reason for this difference is unclear. We speculate on the reasons as follows. First, V-CPF and IV-CPF employ different pathways to generate coughing. ${ }^{22-25}$ The voluntary cough, which is controlled by the cerebral cortex, is initiated by irritation or voluntary action and can be inhibited by conscious patients. If a patient is told to do so, voluntary coughing can be depressed by $90 \%$ when capsaicin is inhaled. ${ }^{22,26}$ On the other hand, the involuntary cough is controlled by the brainstem and is only initiated by irritation when the stimulus reaches a reflex threshold. Moreover, involuntary cough strength is associated with the intensity of the irritation. However, it also can be depressed in conscious patients. ${ }^{22,26}$ In this study, the involuntary cough was stimulated by $2 \mathrm{~mL}$ of normal saline, and different subjects may have had different reflex thresholds. We found that

Table 3. V-CPF Versus IV-CPF in Four Categories of V-CPF in Cooperative Subjects

\begin{tabular}{|c|c|c|c|c|c|}
\hline & \multicolumn{5}{|c|}{ V-CPF } \\
\hline & $\begin{array}{l}\text { Lower Quartile } \\
\text { ( } \leq 43.2 \mathrm{~L} / \mathrm{min} ; \\
29 \text { extubations) }\end{array}$ & $\begin{array}{l}\text { Third Quartile } \\
\text { (43.2-68.4 L/min; } \\
29 \text { extubations) }\end{array}$ & $\begin{array}{l}\text { Second Quartile } \\
\text { (68.4-99.0 L/min; } \\
29 \text { extubations) }\end{array}$ & $\begin{array}{l}\text { Upper Quartile } \\
\text { (> 99.0 L/min; } \\
28 \text { extubations) }\end{array}$ & $\begin{array}{c}\text { Total } \\
\text { (115 extubations) }\end{array}$ \\
\hline $\mathrm{V}-\mathrm{CPF}$ & $33.3 \pm 7.4$ & $55.4 \pm 7.8$ & $82.1 \pm 9.6$ & $135.5 \pm 29.8$ & $76.0 \pm 41.4$ \\
\hline IV-CPF & $38.4 \pm 21.4$ & $53.4 \pm 27.1$ & $66.6 \pm 19.5$ & $116.2 \pm 38.2$ & $68.2 \pm 39.7$ \\
\hline$P$ & .19 & .71 & $<.001$ & .006 & .003 \\
\hline \multicolumn{6}{|c|}{$\begin{array}{l}\text { The } \leq 25 \text { th, } 25 \text { th through } 50 \text { th, } 50 \text { th through } 75 \text { th, and }>75 \text { th percentile of the } \mathrm{V}-\mathrm{CPF} \text { were classified as lower quartile, third quartile, second quartile, and upper quartile, respectively. The } \\
\text { comparison between V-CPF and IV-CPF groups was analyzed by paired sample } t \text { test. } \\
\text { V-CPF }=\text { voluntary cough peak flow } \\
\text { IV-CPF = involuntary cough peak flow. }\end{array}$} \\
\hline
\end{tabular}




\section{Cough Peak Flow for Predicting Re-Intubation}
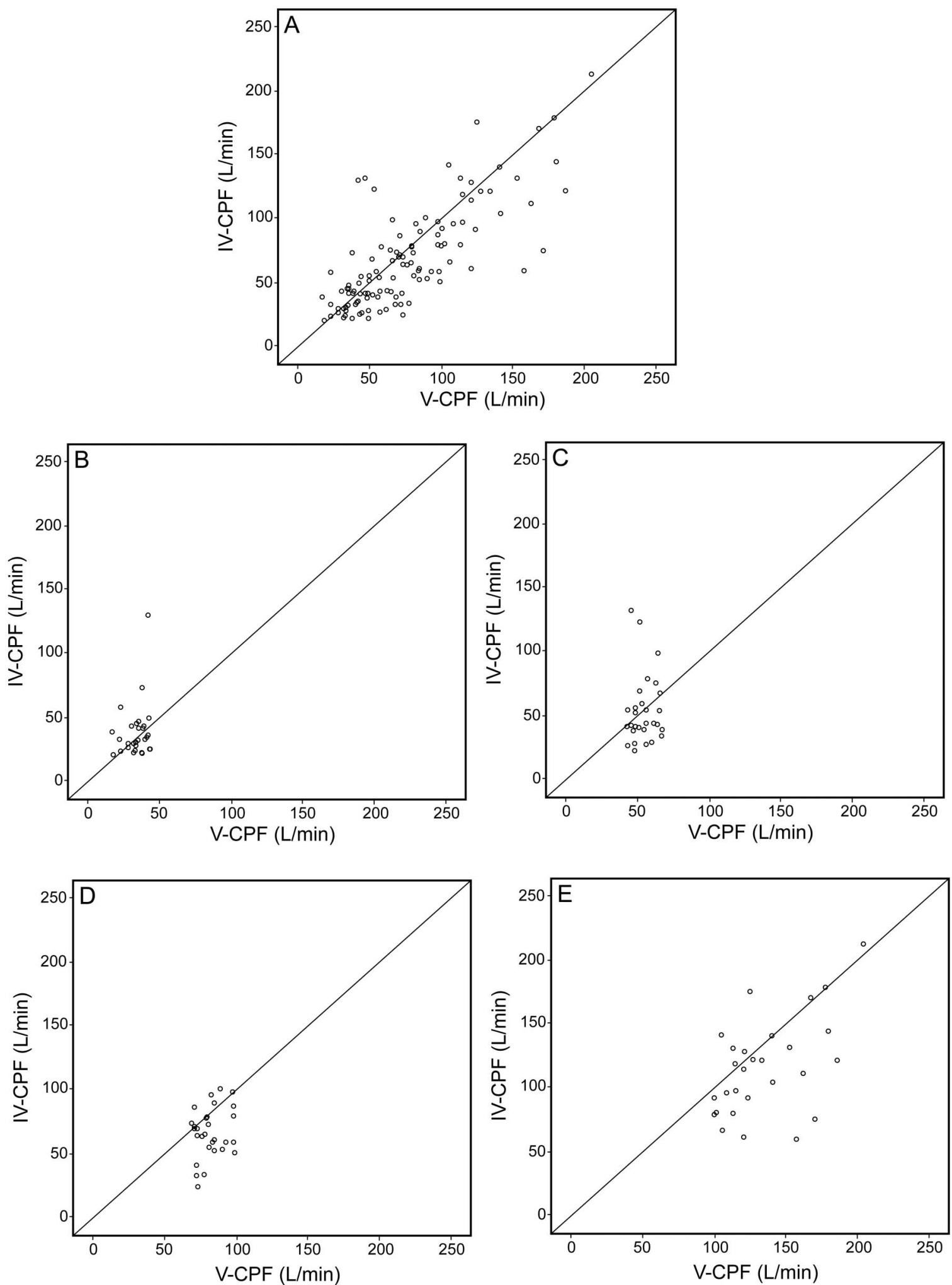

Fig. 3. Distribution of the voluntary cough peak flow (V-CPF) and involuntary cough peak flow (IV-CPF) in A: total population, B: lower quartile, C: third quartile, D: second quartile, and E: upper quartile V-CPF in cooperative subjects. 
Table 4. Characteristics of the Uncooperative Subjects

\begin{tabular}{|c|c|c|c|c|c|}
\hline \multirow{2}{*}{ Subject Characteristics } & \multicolumn{5}{|c|}{ Subject No. } \\
\hline & 1 & 2 & 3 & 4 & 5 \\
\hline Age $(y)$ & 80 & 85 & 69 & 82 & 79 \\
\hline Male/female & $\mathrm{F}$ & M & M & M & $\mathrm{F}$ \\
\hline Causes for initial intubation & Pneumonia & Pneumonia & Pneumonia & Pneumonia & COPD exacerbation \\
\hline Duration of mechanical ventilation before extubation (d) & 12.8 & 3.0 & 2.8 & 7.7 & 6.8 \\
\hline \multicolumn{6}{|l|}{ Data just collected before extubation } \\
\hline GCS & 9 & 10 & 9 & 10 & 12 \\
\hline Breathing frequency (breaths/min) & 22 & 19 & 25 & 30 & 20 \\
\hline Tidal volume $(\mathrm{mL})$ & 284 & 477 & 481 & 440 & 453 \\
\hline Ventilation (L/min) & 6.28 & 9.8 & 12.2 & 12.5 & 8.58 \\
\hline Breathing frequency/tidal volume & 85 & 53 & 52 & 70 & 51 \\
\hline Heart rate (beats/min) & 78 & 69 & 80 & 92 & 64 \\
\hline Systolic blood pressure (mm Hg) & 125 & 105 & 115 & 145 & 126 \\
\hline Diastolic blood pressure $(\mathrm{mm} \mathrm{Hg})$ & 67 & 59 & 73 & 65 & 57 \\
\hline $\mathrm{pH}$ & 7.47 & 7.47 & 7.55 & 7.40 & 7.38 \\
\hline $\mathrm{P}_{\mathrm{aCO}_{2}}(\mathrm{~mm} \mathrm{Hg})$ & 46 & 36 & 28 & 25 & 44 \\
\hline $\mathrm{P}_{\mathrm{aO}_{2}}(\mathrm{~mm} \mathrm{Hg})$ & 119 & 120 & 155 & 87 & 83 \\
\hline $\mathrm{F}_{\mathrm{IO}_{2}}$ & 0.30 & 0.35 & 0.30 & 0.30 & 0.40 \\
\hline $\mathrm{P}_{\mathrm{aO}_{2}} / \mathrm{F}_{\mathrm{IO}_{2}}$ & 397 & 343 & 517 & 290 & 208 \\
\hline V-CPF (L/min) & 45.0 & 47.4 & 34.2 & 49.2 & 25.2 \\
\hline IV-CPF (L/min) & 73.2 & 60.6 & 123.0 & 90.6 & 48.6 \\
\hline Re-intubation at $72 \mathrm{~h}$ & No & Yes & No & No & No \\
\hline $\begin{array}{l}\text { GCS = Glasgow coma scale } \\
\text { V-CPF = voluntary cough peak flow } \\
\text { IV-CPF = involuntary cough peak flow. }\end{array}$ & & & & & \\
\hline
\end{tabular}

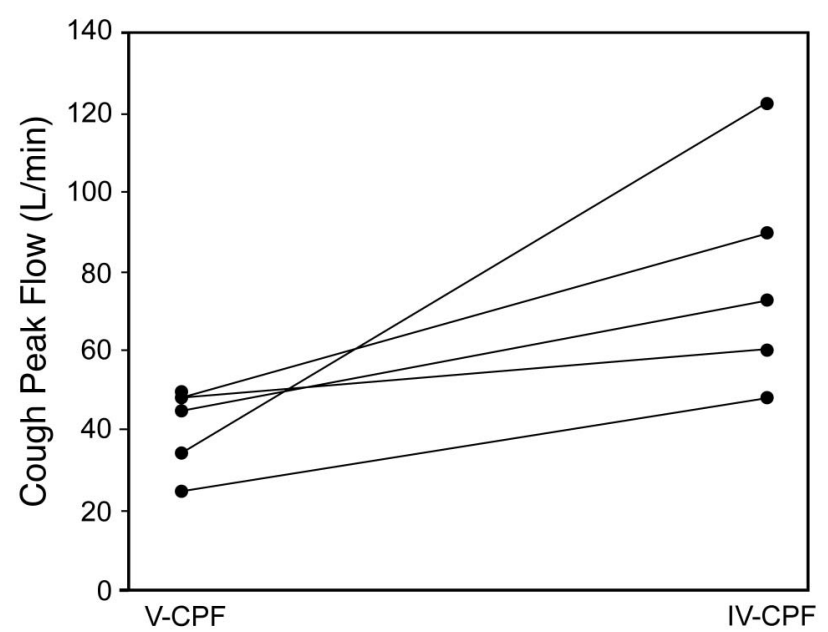

Fig. 4. Comparison of voluntary cough peak flow (V-CPF) and involuntary cough peak flow (IV-CPF) in uncooperative subjects. The V-CPF was lower than IV-CPF (40.2 \pm 10.2 vs $79.2 \pm 29.0$, $P=.04)$.

the IV-CPF was lower than V-CPF in high V-CPF cooperative subjects (Table 3 and Fig. 3). In the high V-CPF cooperative subjects, the IV-CPF may have been partly depressed when the subject felt uncomfortable, or the intensity of irritation of the IV-CPF may not have reached its maximum via instillation of $2 \mathrm{~mL}$ of normal saline, or both. Furthermore, in our study, the V-CPF was initiated by voluntary action. By contrast, the IV-CPF was initiated by $2 \mathrm{~mL}$ of normal saline. The different initial phase may result in different values. Thus, in the high V-CPF cooperative subjects, this amount of saline may result in underestimation of cough strength by IV-CPF.

Furthermore, the instillation of normal saline may make a patient uncomfortable, although $\mathrm{Su}$ et al ${ }^{16}$ observed no obvious side effects or complications. Several studies reported that oxygen saturation decreased when normal saline was instilled before suctioning, compared with the conventional suctioning technique. ${ }^{27-30}$ In this study, we observed that some subjects felt uncomfortable and the oxygen saturation decreased when the IV-CPF was measured after instillation of $2 \mathrm{~mL}$ of normal saline. However, the measurement of $\mathrm{V}-\mathrm{CPF}$ is noninvasive, and therefore, desaturation can be avoided.

The measurement of V-CPF required subject cooperation. However, it is difficult to carry out in uncooperative patients such as coma patients. In these patients, the IVCPF may be a good choice. In our study, we classified the subjects with Glasgow coma scale $\leq 13$ as uncooperative subjects. We found that the IV-CPF was much higher than V-CPF (Table 4 and Fig. 4). However, we only enrolled 5 


\section{Cough Peak Flow for Predicting Re-Intubation}

uncooperative subjects (1 required re-intubation). Because of the small sample size, we drew no conclusion as to which of the two measurements was better in this population. However, in clinical decision making, we suggest that attending physicians refer to the lower quartile of cough peak flow in uncooperative patients.

Our study has some limitations. Laryngospasm after extubation was not recorded in our ICU. It may be more difficult to distinguish re-intubation caused by weak cough or laryngospasm. Approximately $50 \%$ of subjects had an exacerbation of COPD, which may skew the results. Reintubation occurred for various reasons. In this study, we found the re-intubated subjects had longer duration of mechanical ventilation before extubation (Table 1). A previous study demonstrated that patients with long periods of mechanical ventilation had high rates of respiratory failure after extubation..$^{31}$ Thus, to prevent re-intubation, it was not adequate for caregivers to pay attention only to the weak cough peak flow subjects. Furthermore, the reason the two cough peak flow measurements showed different predictive accuracy in cooperative subjects is unclear. Further studies should explore this mechanism. Third, we drew no conclusions in uncooperative subjects because of the small sample size. Thus, in the future, it would be worthwhile to explore this population.

\section{Conclusions}

$\mathrm{V}-\mathrm{CPF}$ as a noninvasive measurement was better than IV-CPF at predicting re-intubation in scheduled extubated cooperative subjects. IV-CPF measurements may underestimate cough strength in patients with high V-CPF. However, in uncooperative patients, the optimum measurement is unclear.

\section{REFERENCES}

1. MacIntyre NR, Cook DJ, Ely EW Jr, Epstein SK, Fink JB, Heffner $\mathrm{JE}$, et al. Evidence-based guidelines for weaning and discontinuing ventilatory support: a collective task force facilitated by the American College of Chest Physicians; the American Association for Respiratory Care; and the American College of Critical Care Medicine. Chest 2001;120(6 Suppl):375S-395S.

2. Boles JM, Bion J, Connors A, Herridge M, Marsh B, Melot C, et al. Weaning from mechanical ventilation. Eur Respir J 2007;29(5):10331056.

3. Macintyre NR. Evidence-based assessments in the ventilator discontinuation process. Respir Care 2012;57(10):1611-1618.

4. El Solh AA, Bhat A, Gunen H, Berbary E. Extubation failure in the elderly. Respir Med 2004;98(7):661-668.

5. Navalesi P, Frigerio P, Moretti MP, Sommariva M, Vesconi S, Baiardi P, Levati A. Rate of reintubation in mechanically ventilated neurosurgical and neurologic patients: evaluation of a systematic approach to weaning and extubation. Crit Care Med 2008;36(11):2986-2992.

6. Solsona JF, Diaz Y, Vazquez A, Pilar Gracia M, Zapatero A, Marrugat J. A pilot study of a new test to predict extubation failure. Crit Care 2009;13(2):R56.
7. Liu Y, Wei LQ, Li GQ, Lu FY, Wang H, Zhang YH, Cao WL. A decision-tree model for predicting extubation outcome in elderly patients after a successful spontaneous breathing trial. Anesth Analg 2010;111(5):1211-1218.

8. Hayashi LY, Gazzotti MR, Vidotto MC, Jardim JR. Incidence, indication and complications of postoperative reintubation after elective intracranial surgery. Sao Paulo Med J 2013;131(3):158-165.

9. Epstein SK, Ciubotaru RL. Independent effects of etiology of failure and time to reintubation on outcome for patients failing extubation. Am J Respir Crit Care Med 1998;158(2):489-493.

10. Rothaar RC, Epstein SK. Extubation failure: magnitude of the problem, impact on outcomes, and prevention. Curr Opinion Crit Care 2003;9(1):59-66.

11. Menon N, Joffe AM, Deem S, Yanez ND, Grabinsky A, Dagal AH, et al. Occurrence and complications of tracheal reintubation in critically ill adults. Respir Care 2012;57(10):1555-1563.

12. Smina M, Salam A, Khamiees M, Gada P, Amoateng-Adjepong Y, Manthous CA. Cough peak flows and extubation outcomes. Chest 2003;124(1):262-268.

13. Beuret P, Roux C, Auclair A, Nourdine K, Kaaki M, Carton MJ. Interest of an objective evaluation of cough during weaning from mechanical ventilation. Intensive Care Med 2009;35(6):1090-1093.

14. Salam A, Tilluckdharry L, Amoateng-Adjepong Y, Manthous CA. Neurologic status, cough, secretions and extubation outcomes. Intensive Care Med 2004;30(7):1334-1339.

15. Gao XJ, Qin YZ. [A study of cough peak expiratory flow in predicting extubation outcome]. Chinese Crit Care Med (Zhongguo Weizhongbing Jijiuyixue) 2009;21(7):390-393.

16. Su WL, Chen YH, Chen CW, Yang SH, Su CL, Perng WC, et al. Involuntary cough strength and extubation outcomes for patients in an ICU. Chest 2010;137(4):777-782.

17. Duan J, Guo S, Han X, Tang X, Xu L, Xu X, et al. Dual-mode weaning strategy for difficult-weaning tracheotomy patients: a feasibility study. Anesth Analg 2012;115(3):597-604.

18. Hanley JA, McNeil BJ. A method of comparing the areas under receiver operating characteristic curves derived from the same cases. Radiology 1983;148(3):839-843.

19. Youden WJ. Index for rating diagnostic tests. Cancer 1950;3(1):3235.

20. Mokhlesi B, Tulaimat A, Gluckman TJ, Wang Y, Evans AT, Corbridge TC. Predicting extubation failure after successful completion of a spontaneous breathing trial. Respir Care 2007;52(12):1710-1717.

21. Khamiees M, Raju P, DeGirolamo A, Amoateng-Adjepong Y, Manthous CA. Predictors of extubation outcome in patients who have successfully completed a spontaneous breathing trial. Chest 2001; 120(4):1262-1270.

22. Lee PC, Cotterill-Jones C, Eccles R. Voluntary control of cough. Pulm Pharmacol Ther 2002;15(3):317-320.

23. Magni C, Chellini E, Lavorini F, Fontana GA, Widdicombe J. Voluntary and reflex cough: similarities and differences. Pulm Pharmacol Ther 2011;24(3):308-311.

24. Widdicombe JG, Addington WR, Fontana GA, Stephens RE. Voluntary and reflex cough and the expiration reflex; implications for aspiration after stroke. Pulm Pharmacol Ther 2011;24(3):312-317.

25. Widdicombe J, Singh V. Physiological and pathophysiological downregulation of cough. Respir Physiology Neurobiol 2006;150(2-3): 105-117.

26. Hutchings HA, Eccles R, Smith AP, Jawad MS. Voluntary cough suppression as an indication of symptom severity in upper respiratory tract infections. Eur Respir J 1993;6(10):1449-1454.

27. Ackerman $\mathrm{MH}$. The effect of saline lavage prior to suctioning. Am J Crit Care 1993;2(4):326-330. 


\section{Cough Peak Flow for Predicting Re-Intubation}

28. Ackerman MH, Mick DJ. Instillation of normal saline before suctioning in patients with pulmonary infections: a prospective randomized controlled trial. Am J Crit Care 1998;7(4):261-266.

29. Hagler DA, Traver GA. Endotracheal saline and suction catheters: sources of lower airway contamination. Am J Crit Care 1994;3(6): 444-447.
30. Kinloch D. Instillation of normal saline during endotracheal suctioning: effects on mixed venous oxygen saturation. Am J Crit Care 1999;8(4):231-240; quiz 241-232.

31. Sellares J, Ferrer M, Cano E, Loureiro H, Valencia M, Torres A. Predictors of prolonged weaning and survival during ventilator weaning in a respiratory ICU. Intensive Care Med 2011;37(5):775-784.

This article is approved for Continuing Respiratory Care Education credit. For information and to obtain your CRCE

(free to AARC members) visit

www.rcjournal.com 